\title{
ВЛИЯНИЕ ПОВЫШЕНИЯ ПЕНСИОННОГО ВОЗРАСТА В КАЗАХСТАНЕ НА ЭФФЕКТИВНОЕ ИСПОЛЬЗОВАНИЕ БЮДЖЕТНЫХ СРЕДСТВ * А.А.Жантаева ${ }^{1}$, А.М.Даузова ${ }^{2}$, Б.О.Туребекова ${ }^{3}$ \\ 1,2 Алматинская академия экономики и статистики, г. Алмать, Казахстан \\ ${ }^{3}$ Казахский университет технологии и бизнеса, Нур-Султан, Казахстан
}

e-mail: aigul_0905@mail.ru

Аннотация. Проведенные реформы показали, что основные причины низкой покупательной способности трудовых пенсий по старости, зависит от демографических, социально-трудовых и других факторов, формируюшимися вне пенсионной системы. В статье рассматривается, какого положительного эффекта для бюджета будет являться повышение пенсионного возраста женщин с 58 лет до 63 года. Сделан прогнозный расчет экономии для бюджета средней пенсии в разрезе возрастных групп женщин-пенсионеров с 2020 г. по 2027 г. Отличительной чертой предлагаемого исследования данного вопроса является то, что основные оченки строятся на прогнозе количества женщин - пенсионеров с разбивкой их по возрастным группам и в расчете предстоящего начисления солидарной пенсии и соответствующих выплат из фондов в среднем по возрастной группе.

Ключевые слова. пенсионный возраст, гендерный разрыв, продолжительность жизни, Индекс Джини, возрастная группа.

Введение. Демографические сдвиги в структуре населения, ведущие к увеличению доли пожилого населения, но и растущая зависимость пенсионной системы от бюджетных средств подтолкнули к пересмотру пенсионного законодательства. В результате был принят Закон РК, который повышает возраст выхода женщин на пенсию поэтапно, добавляя по 6 месяцев каждый год, с 58 до 63 лет с 2018 года [1]. Это мера посчиталась необходимой, по крайней мере, по двум очевидным причинам:

- во - первых, с повышением пенсионного возраста для женщин появится возможность работать дольше, увеличивая собственные накопления, от которых зависит размер пенсии будущем.

- во-вторых, реформа даст возможность более эффективного расходования средств бюджета в долгосрочной перспективе.

Материалы и методы исследования. Анализ численности населения по возрастному составу показал, что средний возраст населения Казахстана за 2015 -2020 годы уменьшился с 31,6 до 29,3 лет. Если сравнить структуры возрастных групп за 2015 и 2020 годы, то можно заметить, Казахстан пока относится к странам стационарного или омолаживающегося типа развития, но при демографическом застое намечается переход от стационарного к регрессивному типу развития, (табл. 1).

Таблица 1. Структура возрастных групп населения $Р К$

\begin{tabular}{|c|c|c|c|c|}
\hline \multirow[t]{2}{*}{ Возраст } & \multicolumn{2}{|c|}{2015} & \multicolumn{2}{|c|}{2020} \\
\hline & Мужчина & Женщина & Мужчина & Женщина \\
\hline $0-14$ & 2252262 & 2378138 & 2087950 & 1999057 \\
\hline $15-49$ & 4565530 & 4457355 & 6561616 & 6904490 \\
\hline 65 и выше & 767198 & 420938 & 479531 & 921155 \\
\hline
\end{tabular}

С 2015 года в Казахстане ожидается снижение доли трудоспособного населения и увеличение доли населения пенсионного возраста, что будет продолжаться вплоть до 2027 года.

С другой стороны, гендерный разрыв в возрасте выхода на пенсию оказывает существенное влияние на размер пенсионных выплат. Это обусловлено, во-первых, более низким уровнем заработной платы женщин. В настоящее время размер среднемесячной заработной платы женщин, по Казахстану в целом, составлял от 66 до 68\% среднемесячной заработной платы мужчин. Во-вторых, различиями в ожидаемой продолжительности жизни женщин и мужчин.

Результаты и обсуждения. Из рейтинга «Rating.kz» составленных 60 стран по продолжительности жизни после выхода на пенсию Казахстан занимает 53 место [2]. В таблице 2 представлена выборка 18 стран из этого списка для исследования. В выборку вошли страны, накопительные пенсионные системы, элементы которых были взяты за основу при разработке казахстанской системы, а также некоторые страны СНГ (табл. 2). 
Таблица 2. Выборка стран по рейтингу продолжительность жсизи на пенсии

\begin{tabular}{|c|c|c|c|c|c|c|c|c|}
\hline \multirow[t]{2}{*}{ Страна } & \multirow{2}{*}{$\begin{array}{l}\text { Средняя } \\
\text { пенсия } \\
(50 \% \text { от } \\
\text { размера } \\
\text { зарплаты) } \\
\text { в месяц }\end{array}$} & \multicolumn{2}{|c|}{$\begin{array}{l}\text { Возраст выхода } \\
\text { на пенсию по } \\
\text { старости }\end{array}$} & \multicolumn{2}{|c|}{$\begin{array}{l}\text { Ожидаемая } \\
\text { продолжительно } \\
\text { сть жизни }\end{array}$} & \multicolumn{2}{|c|}{$\begin{array}{l}\text { Продолжительно } \\
\text { сть жизни на } \\
\text { пенсии }\end{array}$} & \multirow[t]{2}{*}{$\begin{array}{l}\text { Индекс } \\
\text { Джини } \\
(\%)\end{array}$} \\
\hline & & муж & жен & муж & жен & муж & жен & \\
\hline Чили & $\$ 250$ & 65 & 60 & 77 & 82 & 16,3 & 25,3 & 45,9 \\
\hline Швеция & $\$ 2010$ & 61 & 61 & 81 & 84 & 22,2 & 24,8 & 25,7 \\
\hline $\begin{array}{l}\text { Великобрита } \\
\text { ния }\end{array}$ & $\$ 700$ & 65 & 65 & 80 & 83 & 18,0 & 20,5 & 32,8 \\
\hline Франщия & $\$ 1180$ & 62 & 62 & 80 & 86 & 21,8 & 25,9 & 29,9 \\
\hline Дания & $\$ 2800$ & 65 & 65 & 79 & 83 & 17,3 & 20,2 & 25,3 \\
\hline Италия & $\$ 583$ & 67 & 67 & 81 & 85 & 16,2 & 19,6 & 33,3 \\
\hline Польша & $\$ 380$ & 65 & 60 & 74 & 82 & 14,1 & 24,1 & 32,1 \\
\hline Германия & $\$ 1200$ & 65 & 65 & 79 & 83 & 16,8 & 20,3 & 29,0 \\
\hline Норвегия & $\$ 1542$ & 62 & 62 & 81 & 84 & 21,2 & 24,1 & 24,9 \\
\hline США & $\$ 1164$ & 66 & 66 & 76 & 81 & 15,8 & 18,7 & 37,8 \\
\hline Россия & $\$ 285$ & 61 & 56 & 66 & 77 & 15,1 & 25,8 & 43,9 \\
\hline Япония & $\$ 717$ & 62 & 62 & 81 & 87 & 21,7 & 26,9 & 29,9 \\
\hline Литва & $\$ 298$ & 64 & 63 & 70 & 80 & 13,1 & 20,4 & 34,2 \\
\hline Беларусь & $\$ 175$ & 62 & 57 & 69 & 79 & 13,9 & 25,3 & 25,2 \\
\hline Украина & $\$ 142$ & 60 & 60 & 68 & 77 & 16,2 & 21,2 & 26,3 \\
\hline Болгария & $\$ 280$ & 65 & 62 & 71 & 78 & 12,3 & 19,9 & 33,9 \\
\hline Казақстан & $\$ 210$ & 63 & 64 & 67 & 75 & 12,0 & 15,7 & 28,8 \\
\hline Латвия & $\$ 353$ & 64 & 64 & 70 & 80 & 13,3 & 19,1 & 36,3 \\
\hline
\end{tabular}

Как следует из таблицы 2, что максимальный возраст выхода на пенсию установлен в Японии, а также в Японии достигнута самая высокая продолжительность жизни (мужчин - 81 лет, женщин -87 лет). Минимальный возраст выхода на пенсию сохранился в некоторых странах СНГ (Россия, Белоруссия). Минимальная продолжительность жизни, после выхода на пенсию, в странах Беларусь, Болгария, Литва, Казахстан, Латвия. После выхода на пенсию женщины в Казахстане продолжительность жизни равно 16 лет, а средняя продолжительность жизни, после выхода на пенсию равно 13 лет. Если рассмотрим медиальные значения выборок, то следует отметить, что возраст выхода на пенсию и для мужчин и для женщин в Казахстане, ниже серединных значений группы (для мужчин $63<65$, для женщин $58<65$ ). Ещё ниже медиального значения ожидаемая продолжительность жизни, у мужчин $67<76$ (10 лет), особенно у женщин 75<80,5 (5,5 лет). Следовательно, среди данной выборки и выборки из 60 стран (13,8 лет) в Казахстане одна из самых низких продолжительность жизни, после выхода на пенсию. После 2018 года, в результате повышения пенсионного возраста для женщин, Казахстан в рейтинге стран по продолжительности жизни, после выхода на пенсию опустился ещё ниже.

Индекс Джини, приведенный в таблице 2, позволяет сравнить страны по показателю неравенства доходов. Чем выше индекс, тем сильнее расслоение общества, максимальное значение $100 \%$ означает абсолютное неравенство. Как следует из таблицы 2 наибольшее неравенство населения по доходам в Чили $(45,9)$, наименьшее в Швеции $(25,7)$, Дания $(25,3)$, Норвегия $(24,9)$. Из стран бывшего СССР этот индекс имеет наибольшее значение в России $(43,9)$, в Казахстане он равен 28,8\%, наименьшее значение он имел в Белоруссии. За период с 2015 по 2020 годы в Казахстане индекс значительно повысился: от значения 0,269 до 0,288. Такое значение индекса Джини означает более умеренного распределения доходов в РК и присутствие явной социальной напряженности.

Такое значение индекса Джини означает более умеренного распределения доходов в РК и присутствие явной социальной напряженности. Так как согласно программе Целей развития Тысячелетия значение индекса Джини подразделяется по следующим значениям:

- от 0,2 до 0,3 - предельное значение умеренного неравенства;

- от 0,3 до 0,4 - заметное неравенство;

- от 0,4 до 0,5 - значение значительного неравенства по доходам в обществе [3]. 
В связи с проведенным выше анализом при переходе к новому этапу пенсионной реформы необходимо стремится не только к снятию нагрузки на бюджет, но и учитывать, как это повлияет на социальную составляющую.

Рассмотрим, более конкретно, влияние повышения пенсионного возраста женщин с 58 лет до 63 года, в течение 10 лет на государственный бюджет в долгосрочной перспективе (до 2027 г).

Статистические данные распределения количества женщин по возрастным группам, длиной по 5 лет. Информации по распределению внутри группы не имеется. Но в связи небольшого временного интервала группы, можно предположить, что распределение числа женщин по возрасту внутри группы равновероятны. Тогда, исходя из логичных рассуждений, при прогнозе на первый год 4/5 части количества женщин из базового года (это последний год, по которому имеются статистические данные) останется в этой возрастной категории, а 1/5 перейдет в следующую возрастную категорию. Затем в текущую возрастную группу перейдет 1/5 часть из предыдущей возрастной категории.

В следующем году из базового года останется 3/5, а $2 / 5$ женщин базового года перейдет в последующую возрастную категорию и т.д. пока вся предыдущая группа не перейдет в текущую возрастную группу. Далее алгоритм расчета повторяется до 2027 года. По данному алгоритму составлена таблица прогнозного распределения количества женщин по возрастным группам. Из неё отобраны данные по состоявшимся пенсионерам, и о тех, кому предстоит выйти на пенсию к 2027 году (когда возрастной ценз выхода женщин на пенсию будет равен 63 годам) с учетом коэффициента смертности по каждой возрастной группе женщин (табл.3).

Таблица 3. Коэффициенты смертности женщин по возрастным группам

\begin{tabular}{|l|l|l|l|l|l|l|l|l|}
\hline Возраст & Всего & $55-59$ & $60-64$ & $65-69$ & $70-74$ & $75-79$ & $80-84$ & $85+$ \\
\hline общий & 8,94 & 16,17 & 23,3 & 33,06 & 49,81 & 76,31 & 122,57 & 203,96 \\
\hline женщины & 7,71 & 9,78 & 14,81 & 22,68 & 37,63 & 63,85 & 113,03 & 205,37 \\
\hline
\end{tabular}

Полученная прогнозная динамика количества женщин по группам, пред пенсионного и пенсионного возраста представлена на рисунке 1.

Из диаграммы (рис.1) следует что, почти по всем возрастным группам наблюдается рост численности женщин, особенно по первым трем, причем наименьшие значения в каждой группе составляет число женщин, год рождения которых приходится на военные и первые послевоенные годы. Так как возрастной ценз выхода на пенсию до 2018 года равен 58 годам, то из группы 55-59 лет, только женщины, возраст которых попадает в интервал $(58,59)$ и $(59,60)$ относятся к пенсионерам, допустим, что это $2 / 5$ числа женщин всей группы.

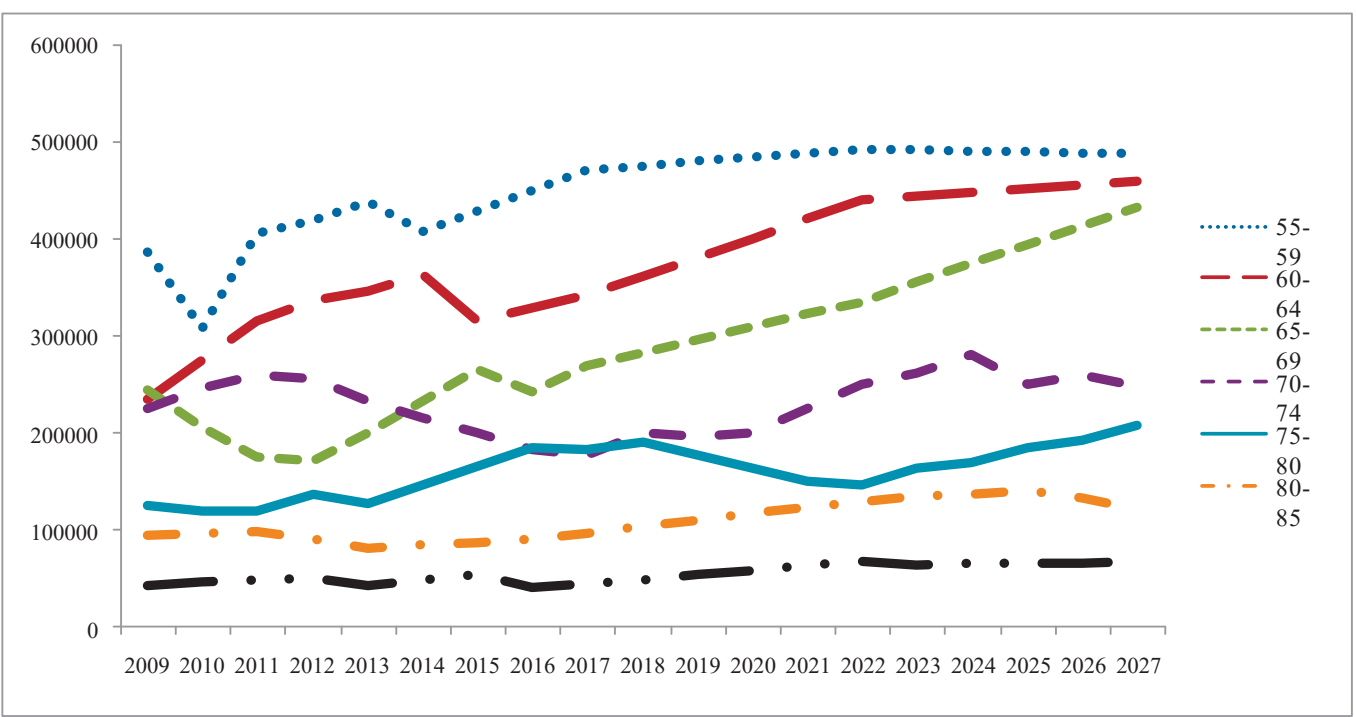

Рисунок 1 - Прогнозная динамика численности женщин в разрезе возрастных групп Примечание - Построено по данным [3]. 
С учетом данного предположения было рассчитано прогнозное значение числа пенсионеровженщин за каждый анализируемый год. Причем произведено два варианта расчета, исходя из пенсионного возраста - 58 лет до 2027 года и по новому возрастному цензу, начиная с 2018 г. Для более наглядного представления результатов построена диаграмма сравнения двух вариантов расчетов по старому возрастному цензу 58 лет и по новому - 63 года (рис. 2).

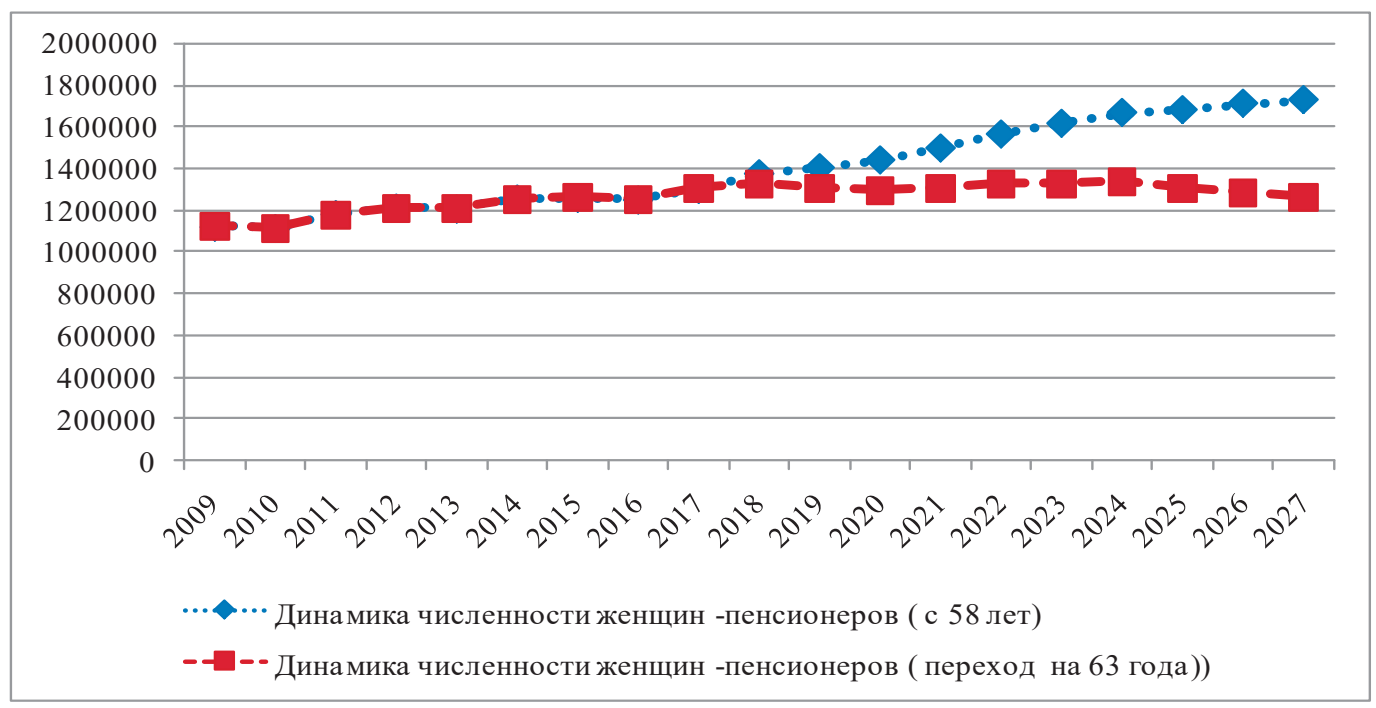

Рисунок 2 - Сравнение динамики числа женщин-пенсионеров

Примечание - Построено автором

Представленная диаграмма показывает, что число женщин - пенсионеров при возрастном цензе 58 лет имеет тенденцию роста, а при переходе на пенсионный возраст с 63 лет, число женщин - пенсионеров постепенно стабилизируется. Сокращение числа женщин пенсионного возраста, не выйдут на пенсию, в связи с переходом на новую систему, по годам приведено в таблице 4.

Таблица 4. Сокращчение числа женщуин- пенсионеров

\begin{tabular}{|l|l|l|l|l|l|l|l|l|}
\hline Годы & 2020 & 2021 & 2022 & 2023 & 2024 & 2025 & 2026 & 2027 \\
\hline $\begin{array}{l}\text { Число } \\
\text { женщин }\end{array}$ & 145049 & 195044 & 240780 & 285279 & 330548 & 376587 & 423396 & 470976 \\
\hline
\end{tabular}

Представленные данные показывают, что в 2027 г. число женщин, не вышедших на пенсию, в связи изменением возрастного ценза составит около 500 тыс. человек.

Большинство авторов при расчете экономии для бюджета в связи с пенсионной реформой, исходят из средней пенсии в 2020 г., равной 42319 тенге, и в последующие годы берут повышение средней пенсии на 6\% - 7\% ежегодно [4]. Однако, в реальности, солидарный компонент пенсии (без учета базовой) изменяется более медленным темпом. А в перспективе (с 2020 г.), эта составляющая пенсии даже будет сокращаться, в связи с тем, что при расчете солидарной пенсии стаж засчитывается только до 1998 г. (рис. 3).

С 1 июля 2018 года солидарная часть пенсий исчисляется с учетом совокупного трудового стажа до 1 января 1998 года и стаж участия в накопительной пенсионной системе с 1 января 1998 года. Для более точного прогноза расчеты средней пенсии были произведены в разрезе возрастных групп женщинпенсионеров с 2020 г. по 2027 г.

Для расчета солидарной пенсии с учетом базового компонента разработан алгоритм в Excel, на основании которого результирующие показатели: «Назначенные пенсионные выплаты», и «Пенсионные выплаты, включая базовую пенсию, в тенге» рассчитываются автоматически, согласно Закону РК «О пенсионном обеспечении в Республике Казахстан». Рассмотрены два варианта расчетов, первый - выход на пенсию по старой схеме в 58 лет; второй - постепенный переход на пенсионный возраст 63 года. 


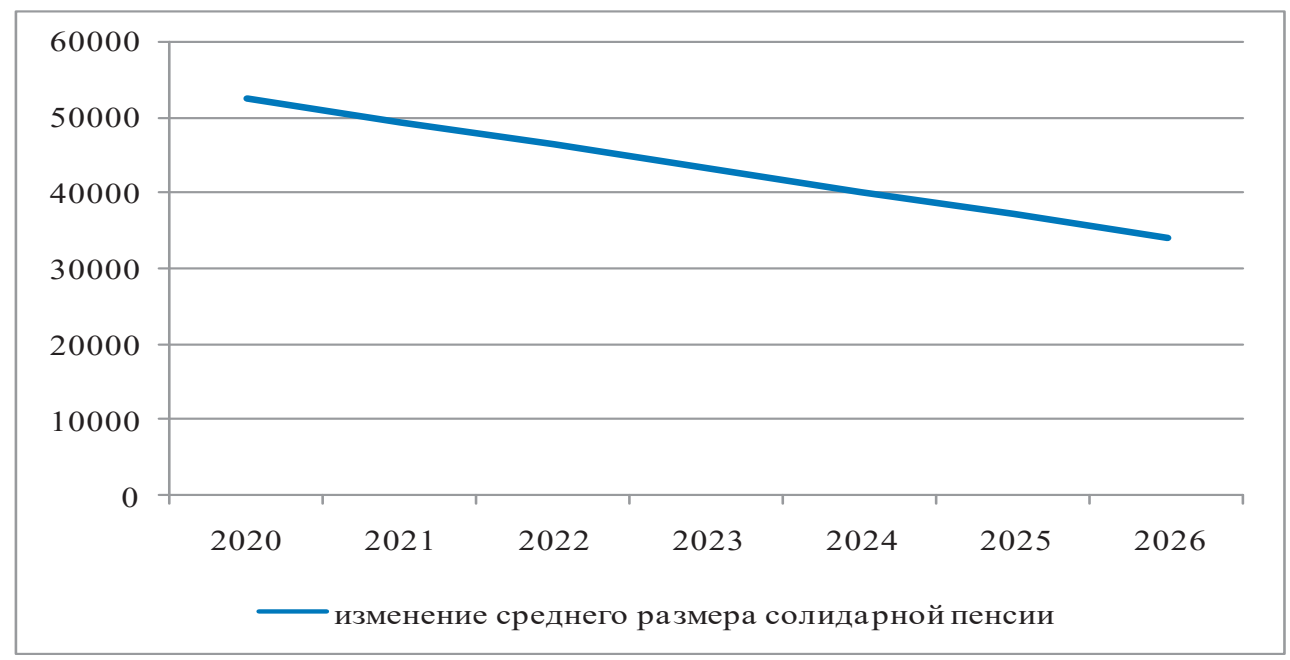

Рисунок 3 - прогноз снижения солидарной части пенсии (без учета базовой)

Примечание - Построено автором на основе данных [5]

На основании средней зарплаты, МРП, МЗП, базовой пенсии за исследуемые годы, рассчитаны средние значения пенсия по возрастным группам в момент выхода на пенсию, с учетом последующих ежегодных повышений согласно Закону о республиканском бюджете [6]. В результате экономия в первый год составит 3,5 млрд. тенге и достигнет 41 млрд. тенге в 2027 г., после чего стабилизируется. Всего, экономия за переходный период составит 207 млрд. тенге.

Заключение. Из проведенного анализа можно увидеть, что повышение пенсионного возраста женщин будет способствовать снижению гендерного неравенства в размерах устанавливаемых пенсий по возрасту. Но положительный эффект для бюджета будет кратковременным. В первое время дефицит будет уменьшаться, потому что на первых порах станет меньше пенсионеров, затем «отложенные» граждане начнут выходить на пенсию.

Расчет, проведенный нами, показал, что экономия бюджетных средств до 2027 года составит 207 млрд. тенге. Затем процесс стабилизируется, тем более, что возможность этой меры согласуется с наметившейся тенденцией роста продолжительности жизни населения, и как следствие, увеличением количества лет дожития нынешних пенсионеров.

Список использованной литературы:

1 Закон РК от 21.06.2013 № 105-V «О пенсионном обеспечении в Республике Казахстан».

2 ОО «Казпотрепнадзор» http://www.rating.kz//

3 Кусаинова А. Е. Анализ дифференциации населения по уровню доходов// Экономика и статистика, №1 Агентство РК по статистике: Астана 2019 г.

4 Демографический ежегодник Казахстана. Агентство Республики Казахстан по статистике: Нур-Султан. 2019 г.

5 Сулейменов О. Пенсионный возраст: Повысить нельзя оставить//Эектронный ресурс: http://www.kursiv.kz//news/

6 Закон РК О внесении изменений в Закон Республики Казахстан «О республиканском бюджете на 2019-2021 годы».

\section{List of used literature:}

1 Law of the Republic of Kazakhstan dated June 21, 2013 No. 105-V "On Pension Provision in the Republic of Kazakhstan".

2 PA "Kazpotrepnadzor" http://www.rating.kz//

3 Kusainova A.E. Analysis of population differentiation by income level // Economy and statistics, No. 1 Agency of the Republic of Kazakhstan on statistics: Astana 2019

4 Demographic Yearbook of Kazakhstan. Agency of the Republic of Kazakhstan on Statistics: NurSultan. Dec 2019

5 Suleimenov O. Retirement age: It is impossible to leave it // Electronic resource: http://www.kursiv.kz//news/

6 Law of the Republic of Kazakhstan On Amendments to the Law of the Republic of Kazakhstan "On the Republican Budget for 2019-2021". 


\section{ҚАЗАҚСТАНДА ЗЕЙНЕТ ЖАСЫН ҰЛҒАЙТУДЫН БЮДЖЕТ ҚАРАЖАТЫН ТИІМДІ ПАЙДАЛАНУҒА ӘСЕРІ \\ *А.А.Жантаева ${ }^{1}$, А.М.Даузова ${ }^{2}$, Б.О.Туребекова ${ }^{3}$

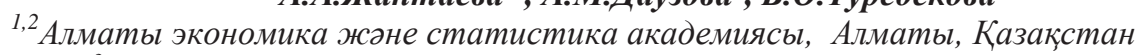 \\ ${ }^{3}$ Казақ технология және бизнес унивеститеті, Нұр-Сұлтан, Қазақстан e-mail: aigul_0905@mail.ru}

Tүйін. Зейнетақы жүйесіне жүргізілген реформалар, жасы бойынша алатын зейнетақьва қ̧ол жеткізу мүмкіндігінің төмендігі, зейнетақы жүйесінен тыс қалыптасатын демографиялық, длеуметтік, енбек және басқ̧а факторларва тәуелді екенін көрсетті. Бұл тұрвыдан дйелдердің зейнетке шыву жасының 58-ден 63 жасқ̧а дейін көтерілуі мемлекет бюджетіне қ̧андай көлемде және қ̧алай әсер ететіні есептелініп нақты сандық деректермен көрсетілген. 2020 жылдан бастап 2027 жылга дейінгі аралықта зейнеткерлікке шыққан дйелдердің жас топтары тұрzысынан орташа зейнетақы бюджеті бойынша жинақтаудың болжамдық есептеулері жасалды. жас тобы.

Түйінді сөздер: зейнеткерлік жас, гендерлік алшақтық, өмір сүру ұзақтыъъы, Джини индексі,

\section{INFLUENCE OF INCREASING THE RETURN AGE IN KAZAKHSTAN ON EFFECTIVE USE OF BUDGETARY FUNDS \\ *A.A.Zhantaeva ${ }^{1}$, A.M.Dauzova ${ }^{2}$, B.O.Turebekova ${ }^{3}$ \\ ${ }^{1,2}$ Almaty Academy of Economics and Statistics, Almaty, Kazakhstan \\ ${ }^{3}$ Kazakh University of Technology and Business, Nur-Sultan, Kazakhstan \\ e-mail: aigul_0905@mail.ru}

Summary. The reforms carried out have shown that the main reasons for the low purchasing power of old-age labor pensions depend on demographic, social, labor and other factors that are formed outside the pension system. The article examines what positive effect the retirement age of women will have on the budget from 58 to 63 years. A forecast calculation of the savings for the budget of the average pension was made in the context of the age groups of retired women from 2020 to 2027. A distinctive feature of the proposed study of this issue is that the main estimates are based on the forecast of the number of retired women, broken down by age group and in calculation of the forthcoming accrual of solidary pension and corresponding payments from funds on average for the age group.

Keywords: retirement age, gender gap, life expectancy, Gini index, age group. 